Resumo

O filme I am Sam trata da deficiência mental e das representações sociais que a envolvem. Inicialmente, o artigo pretende apresentar a definição de deficiência mental em uma perspectiva universal e cotejar a diferença entre deficiência mental, debilidade e fracasso escolar na perspectiva da psicanálise, considerando a relação da criança com o saber. Usar do cinema e da filmografia disponivel para interrogar diagnósticos fixos e segregadores, que excluem o sujeito e sua relação com o saber, é o objetivo deste trabalho.

Descritores: deficiência; sujeito; relação com o saber.

\section{AM SAM: DEFICIÊNCIA MENTAL E RELAÇÃO COM O SABER}

\title{
O sujeito e a deficiência mental
}

【números autores já problematizaram o termo "deficiência mental", recolocando o debate acerca da oposição normalidade-doença, que, não raro, exclui a noção de diferença do cenário. Alguns autores apontam o caráter de abrangência dos fenômenos que tal concepção abarca e outros insistem em resgatar o caráter de singularidade que essa dimensão comporta. No comentário do filme I am Sam que farei a seguir, apresento algumas dessas dimensões visando a interrogá-las a partir da psicanálise.

Sean Penn interpreta, em I am Sam, um deficiente mental de forma talentosa e convincente. Sam é um pai com deficiência mental que toma conta de sua filha, Lucy (interpretada por Dakota Fanning), abandonada pela mãe. Ele sofre de um atraso mental, cuja origem o

Psicanalista. Doutora em Educação pela Universidade Federal de Minas Gerais (UFMG). Professora adjunta de Psicologia e do Programa de Pós-Graduação em Educação da Universidade Federal de Ouro Preto (UFOP), Ouro Preto, MG, Brasil. 
filme não deixa clara. De acordo a definição apresentada no filme, Sam possui o corpo de homem e a mentalidade de uma criança de 7 anos.

Nesse caso, podemos destacar duas ordens discursivas: uma que coloca de um lado o sujeito e sua deficiência e outra que situa a deficiência como foco e deixa de lado o sujeito. Parece-me que o filme I am Sam se orienta pela segunda ordem discursiva. Aqui ela será apresentada a fim de que possa concomitantemente interrogá-la a partir da leitura psicanalítica.

A concepção de deficiência predominante no século XX, com incidências ainda no século XXI, é tributária do discurso médico, que considera uma condição determinada pela anomalia de diferentes funções orgânicas e/ou funcionais. Essa concepção tem efeitos sobre as pessoas com deficiência, sobre as famílias e as escolas em relação às marcas de exclusão que provoca, principalmente da dimensão singular. $\mathrm{O}$ modelo médico da deficiência enclausura o sujeito no discurso do inválido, do desamparado, do dependente de cuidados, tornando-se um problema que, uma vez atrelado ao orgânico, não há o que fazer senão adaptar-se à sociedade. Esse modelo, bastante arraigado, é o que impera em uma das definições aceitas mundialmente para designar a deficiência mental e suas características.

Tomo aqui a definição da Organização Mundial da Saúde (OMS) em seu caráter conceitual universal, a fim de nos permitir a interrogação dessa definição mais à frente. A deficiência mental tem sido definida como o desempenho intelectual geral significativamente abaixo da média própria do período de desenvolvimento, concomitante com limitações associadas a duas ou mais áreas da conduta adaptativa ou da capacidade do indivíduo em responder adequadamente às demandas da sociedade, nos seguintes aspectos: comunicação, habilidades sociais, desempenho na família e comunidade, independência na locomoção, saúde e segurança, desempenho escolar, lazer e trabalho que resultam em lentidão para aprender; por vezes, confusão de ideias, falha ou dificuldade de decisão, de interpretação das condições de segurança e de orientação no meio ambiente (OMS, 2011).

Segundo a OMS, $10 \%$ da população em países em desenvolvimento têm algum tipo de deficiência, sendo que metade desse percentual apresenta deficiência mental propriamente dita. Calculase que o número de pessoas com deficiência mental guarda relação com o grau de desenvolvimento do país em questão e, segundo 
estimativas, a porcentagem de jovens de 18 anos e menos que sofrem atraso mental grave se situa em torno de $4,6 \%$, nos países em desenvolvimento, e entre $0,5 \%$ e $2,5 \%$ nos países desenvolvidos (ONU, 2011). Essa diferença demonstra que certas ações preventivas, como, por exemplo, a melhora da atenção materno-infantil e algumas intervenções sociais específicas permitiriam um decréscimo geral dos casos de nascimento de crianças com deficiência mental. Toda a produção de saber nessa ordem discursiva se pauta pela identificação e possível prevenção de causas que possam minimizar os efeitos da deficiência.

\section{Causas e fatores de risco}

Existe uma complexidade de causas, e elementos múltiplos e interativos estão envolvidos na origem da condição de deficiência mental. Conhecer e identificar esses fatores de risco é necessário para que se possam estabelecer programas de prevenção. No entanto, não existe uma correlação obrigatória entre os elementos apontados como causadores da deficiência e a condição deles resultante; ou seja, muitas pessoas expostas a fatores de risco não apresentam deficiência mental. Além disso, é importante ressaltar que, mesmo utilizando sofisticados recursos diagnósticos, muitas vezes não se chega a definir com clareza a causa da deficiência mental.
Entre os fatores de risco e causas pré-natais que incidirão desde a concepção até o início do trabalho de parto, podemos citar aqueles relacionados à saúde materna, como desnutrição, má assistência no período gestacional, doenças infecciosas (sífilis, rubéola, toxoplasmose), fatores tóxicos (alcoolismo, consumo de drogas e tabaco, efeitos colaterais de medicamentos); além da poluição ambiental em larga escala e o tabagismo no meio familiar. Já os fatores genéticos mais conhecidos são as alterações cromossômicas (numéricas ou estruturais), como a síndrome de Down ou a síndrome de Matin Bell; as alterações gênicas, como erros inatos do metabolismo (fenilcetonúria), a síndrome de Williams, a esclerose tuberosa. Fatores de risco e causas perinatais são aqueles que incidirão desde o início do trabalho de parto até o $30^{\circ}$ dia de vida do bebê, e podem incluir: má assistência ao parto e traumas de parto, hipóxia ou anóxia (oxigenação cerebral insuficiente), prematuridade e baixo peso, icterícia grave do recém-nascido, e outros. Os fatores de risco e causas pós-natais são os que ocorrerão do $30^{\circ}$ dia de vida até o final da adolescência, e podem ser: desnutrição, desidratação grave, carência de estimulação global; infecções (meningoencefalites, sarampo); intoxicações exógenas (envenenamento, remédios, inseticidas, produtos químicos como chumbo ou mercúrio). Atualmente, grande parte dos fatores pós-natais é atribuída a acidentes de trânsito, afo- 
gamentos, choque elétrico, asfixia ou quedas, bem como a infestações (um bom exemplo é a neurocisticercose, causada pela larva da Taenia solium) (OMS, 2011).

O atraso no desenvolvimento das pessoas com deficiência mental pode se dar em nível neuropsicomotor, quando a criança demora em firmar a cabeça, sentar, andar, falar. Pode darse ainda em nível de aprendizado, com notável dificuldade de compreensão de normas e ordens e dificuldade no aprendizado escolar. Mas é preciso que haja vários sinais para que se suspeite de Deficiência Mental e, de modo geral, um único aspecto não pode ser considerado indicativo de qualquer deficiência.

Nessa ordem discursiva, reconhece-se que os efeitos da Deficiência Mental entre as pessoas são diferentes. Aproximadamente $87 \%$ dos deficientes mentais têm limitações leves das capacidades cognitivas e adaptativas, e a maioria deles pode chegar a levar suas vidas independentes e integrados na sociedade. Os 13\% restantes podem ter sérias limitações, mas em qualquer caso, com a devida atenção das redes de serviços sociais, também podem integrar-se na sociedade.

Nota-se que, de acordo com Santiago (2005), também nos tratados de psiquiatria infantil publicados no final do século XIX e início do século XX, a orientação classificatória das nosologias passa da análise dos estados para a análise das doenças e de suas causas. Nessa perspectiva, a forma adquirida da deficiência mental (anteriormente denominado retardo mental) é desdobrada, considerando-se também a possibilidade da demência precoce, $\mathrm{O}$ que culmina nos estudos das psicoses também na infância. Numa vertente distinta, situa-se a extensa contribuição de Binet e Simon no campo do retardo mental, com a elaboração do teste de inteligência.

Analisando o protagonista do filme I am Sam, notamos que o diretor transmite a ideia de que a deficiência mental de Sam o impede de aceder a saberes que são próprios da vida adulta, ainda se baseando em uma concepção de deficiência mental que se antecipa ao sujeito. Se há diferenças entre a nosologia de deficiência mental e a debilidade mental nesse campo discursivo, tais diferenças são sutis e em alguns momentos essas categorias se confundem. Já a leitura que a psicanálise faz acerca da debilidade traz uma diferença que será abordada em termos da relação do sujeito com o saber.

$\mathrm{Na}$ mesma esteira discursiva que desconsidera o sujeito do inconsciente, a categoria de debilidade mental se pauta por um elemento deficitário que atravessa as investigações psiquiátricas e mantém-se no domínio da psicologia diferencial. O que a psicometria faz em relação à debilidade é consolidá-la, dando-lhe a qualificação de mental. Desde a psicometria, a expressão "debilidade mental" recebe uma base objetivável ou, ao menos, mensurável em termos de déficit 
com relação a uma competência intelectual julgada estatisticamente normal (Santiago, 2005).

A expressão "debilidade mental" foi forjada por Ernest Dupré, em 1909, para designar um estado patológico da atividade motora. Bruno (1986), psicanalista de Toulouse, França, especialista na questão da debilidade mental, considera que "Dupré estende ao mental uma qualificação até então reservada ao físico". O autor salienta, ainda, o contexto histórico do aparecimento dessa expressão, que é o "da expansão do período imperial francês, ao qual corresponde, como forma de Estado, a terceira República". Bruno acrescenta que essa foi uma fase de extensão qualitativamente nova do sistema escolar, marcada "por uma ideologia de missão civilizadora que não deixa de ter implicações racistas" (p. 38).

De acordo com Santiago (2005), esse contexto terá sua importância na obra de Alfred Binet, que busca estabelecer os graus de debilidade mental por meio da avaliação da competência intelectual dos indivíduos. Em relação a essas escalas diferenciais, sabemos que, ainda nos dias de hoje, elas são utilizadas para fazer o diagnóstico da debilidade. O estabelecimento do Quociente Intelectual ou Quociente de Inteligência (QI) em termos de idade mental é o que serve de operador para se detectarem os sujeitos débeis. Ao fundar-se o diagnóstico da debilidade sobre os instrumentos de medida da psicologia diferencial, perdem-se de vista os elementos teórico-clínicos que vinham norteando a estruturação da clínica pedopsiquiátrica, ainda que baseada em um enfoque deficitário. A autora aponta que mesmo os pesquisadores da Escola de Genebra - como B. Inhelder e J. Piaget, cuja perspectiva genética indica um paralelismo entre os processos de construção e integração das noções de conservação na criança normal e na criança débil - acabam postulando, para a criança com debilidade, uma "fixação" a um estado anterior, pela imperfeição da construção intelectual.

No filme I am Sam, o protagonista tem comportamento típico de um deficiente mental, apresentando tiques e uma linguagem rudimentar que transmitem ao espectador, sem dúvida nenhuma, uma credibilidade, graças à notável interpretação de Sean Penn. Funcional, apesar dos limites impostos pela deficiência, o personagem Sam tem uma casa, um emprego, amigos e uma filha que acaba de completar 7 anos. Até então, ele se mostrava capaz de amar e cuidar de sua filha. $\mathrm{O}$ fato de ela fazer 7 anos de idade, aprender a ler e escrever e apresentar dificuldades no avanço intelectual dessas 
habilidades interroga a capacidade do pai para educá-la. O Estado, representado por uma assistente social, quer tirá-la dos cuidados do pai, alegando que ele não tem condições de criá-la e que, para além do amor e do afeto que esse pai dedicava à filha, era preciso que ele não fosse um deficiente.

Sam se mostra um pai dedicado, alegre, disposto a brincadeiras, ao afeto, e preocupado com o bem-estar da criança, por vezes se colocando também numa posição infantil. Ocorre que ao completar 7 anos a filha Lucy se vê diante de um impasse intelectual, ao constatar que seu pai não ultrapassou alguns limites cognitivos próprios da deficiência mental. Podemos pensar que a menina se vê diante de um quadro de debilidade temporária quando também não se permite aprender mais nada além do que pode saber o seu pai. A questão é percebida por vizinhos e pela assistente social, que passa a acompanhar de perto o caso alegando veementemente que o protagonista não tem condições de educar uma criança e que esta deverá ser adotada por outra família.

Então, podemos inferir que a assistente social e a escola de Lucy também estão calcadas no mesmo referencial teórico que orienta a representação de debilidade mental. Isso evidencia, por um lado, a perda dos referenciais teórico-clínicos e, por outro lado, o poder classificatório dos testes de inteligência na abordagem da debilidade, que se firmou cada vez mais contundentemente como instrumento de avaliação no domínio da educação. A hegemonia do enfoque adaptacionista da psicologia no âmbito da escola confundiu-se, de alguma forma, com a aliança da psiquiatria com a pedagogia.

Os psiquiatras que se dedicavam à reabilitação de crianças identificadas como pouco inteligentes, por meio da utilização de métodos educativos especiais, passaram a tratar essas crianças dentro das escolas, em salas reservadas para esse fim e identificadas como salas de ensino especial. Os centros de reabilitação tinham um custo muito elevado e não estavam encontrando mais subsídios para serem mantidos. O fechamento dos centros favoreceu o deslocamento das crianças anormais e dos psiquiatras para dentro das escolas especiais (Santiago, 2005).

A ótica de reabilitação da debilidade mental proposta pela pedopsiquiatria e seu encontro com a ideologia dos pedagogos abriram as portas da instituição escolar à metodologia diagnóstica da psicologia. Durante as primeiras três décadas do século XX, os testes psicológicos assumiram um grande peso na decisão dos educadores 
a respeito do destino escolar de grandes contingentes de crianças que tinham acesso à escola.

É na esteira desse pensamento que a personagem da assistente social do filme I am Sam se situa ao comparar o comportamento de pais que não têm deficiência mental com o comportamento de Sam para concluir que este não tem condições de criar Lucy. Além disso, a assistente estabelece para Sam e para Lucy a solução em nome do saber que lhe confere a sua especialidade: a menina deverá ser adotada por outra família, desconsiderando tanto a condição de Sam, ainda que deficiente mental, quanto da criança Lucy como sujeitos de desejo.

Para intermediar a questão acerca da desautorização de Sam para cuidar de Lucy, o discurso de outra especialidade é convocado: o discurso jurídico, representado no filme pela personagem (interpretada por Michelle Pfeiffer) de uma bela e bem-sucedida advogada, e também mãe de um filho, porém sem nenhuma deficiência. Mas o filme mostra que, apesar de ser normal, essa criança é infeliz e sua relação com a mãe é bastante difícil, se comparada com a relação de Lucy e Sam. Inicialmente, a advogada também corrobora a descrença na capacidade do pai deficiente de educar a filha, com base numa representação e numa prática que avaliza que todos falem pela criança ou sobre a criança, e, no caso do filme, isso implica que todos falem também pelo pai que tem uma deficiência.

Para Santiago (2005), na deficiência mental, assim como nas demais questões da psiquiatria, a capacidade de adaptação do sujeito ao objeto, ou da pessoa ao mundo, é o elemento mais fortemente ligado à noção de desenvolvimento normal. Teoricamente, já que a unidade de observação é a capacidade de adaptação, deveriam ficar em segundo plano as questões mensuráveis de QI. Esse referencial do desenvolvimento, na medida em que é construído a priori, é incompatível com a clínica do sujeito, com a clínica que contempla elementos da subjetividade.

Embora tradicionalmente a definição de deficiência mental baseada no QI tenha sido adotada por aqueles que estão acostumados a pensar na Deficiência Mental como uma condição em si mesma, um estado patológico bem definido, atualmente essa classificação é bastante questionada pelas teorias de cunho sociointeracionistas, para as quais a Deficiência Mental é, na maioria das vezes, uma condição mental relativa. De acordo com essas teorias, a existência de alguma limitação funcional, principalmente nos 
graus mais leves, não seria suficiente para caracterizar um diagnóstico de Deficiência Mental, se não existir um mecanismo social que atribua a essa limitação um valor de morbidade. E esse mecanismo social que atribui valores é sempre comparativo, portanto, relativo. Nesse sentido, seria mais interessante tomar a deficiência mental como um estado no qual existe de fato uma limitação funcional em qualquer área do funcionamento humano, mas tal limitação seria relativa às limitações das pessoas naquele sistema social em que se insere a pessoa. Isso significaria que uma pessoa poderia ser considerada deficiente em uma determinada cultura e não deficiente em outra, de acordo com a capacidade dessa pessoa de satisfazer as necessidades dessa cultura. Isso tornaria o diagnóstico também relativo. Nessa concepção, podemos assinalar a passagem do modelo médico ao modelo social da deficiência.

No filme, há uma insistência de Sam para se fazer entender pela advogada e para que esta assuma a causa dele, já que ela também não acredita a priori em sua capacidade de cuidar e educar sua filha. O que fica subentendido nas entrelinhas do filme é que, além da questão da deficiência, há um pressuposto subjacente de gênero, pois Lucy é uma menina e, portanto, deveria ser educada por uma mulher. A partir da convivência com Lucy e Sam e da observação da advogada, bem como dos indícios de uma alegria nunca vista em seu próprio filho, 
essa representação da advogada se altera. Quando a questão de quem deve permanecer com a guarda de Lucy se apresenta nos tribunais, se o pai com deficiência ou a família adotiva, a justiça encerra a questão, passando a guarda à mãe adotiva. Dessa vez é Lucy quem fura o cerco e insiste em fazer-se sujeito, fugindo da casa da família adotiva e recorrendo insistentemente à casa do pai.

Podemos inferir, a partir do filme, que a avaliação da pessoa com deficiência deveria ser feita considerando-se sua totalidade. Isso significaria que tanto a assistente social - por meio do estudo e diagnóstico familiar, da dinâmica de relações entre pai e filha e da situação do deficiente na família e na sociedade - quanto a justiça e a escola deveriam analisar de forma conjunta os aspectos socioculturais, buscando alternativas para complementar o que falta à relação entre um sujeito que tem uma deficiência e um sujeito que não a tem, como tem sido feito nos modelos sociais de inclusão do deficiente em casas-lares. O filme nos mostra, tanto em seu decorrer quanto nas cenas finais, que essa é a solução de uma possível cooperação entre os saberes da família adotiva e os saberes do pai, numa relação complementar, e não mais substitutiva. Vejamos como se processa a leitura psicanalítica acerca do saber.

\section{Saber, sujeito do inconsciente, destinos do saber}

Nesta segunda parte do artigo, buscamos interrogar a concepção de saber considerando sua dimensão inconsciente, e não mais um saber prefixado na condição de uma deficiência. Podemos nos perguntar como cada personagem do filme se posiciona na sua relação com o saber para além da deficiência, invertendo a lógica discursiva que orientou o filme. Para a psicanálise, interessa primordialmente o sujeito e sua relação com o saber.

Esse saber, que Freud inaugura, não é considerado conhecimento no sentido tradicional da articulação entre alguém que sabe e a coisa sabida, mas um saber que toma forma de inscrição no discurso do sujeito. Essa dimensão articula o sujeito a um desejo de saber movido pelos enigmas que se lhe apresentam. Presente nos atos e nas escolhas que o sujeito faz, nem sempre, porém, esse saber pode ser nomeado. 
Para a psicanálise, o saber é da ordem de uma elaboração pessoal, de algo a ser estabelecido e tecido pelo sujeito. Esse saber que trabalha o sujeito e no sujeito, às vezes, à sua revelia, interfere nas suas posições diante das diversas situações da vida. De ordem inconsciente, tal saber designa o conjunto de determinações que regem a vida de um sujeito. Porém, ele é um saber que lhe escapa, no sentido de que ele o ignora. Ignorância ativa, cheia de ambiguidades, ela incide sobre tudo que constitui o tecido, o próprio ser do sujeito: o que ele esqueceu de sua história, dos acontecimentos por ele vividos, dos pensamentos e dos sentimentos que o constituíram e que ainda o constituem; desse saber o sujeito nada sabe, a não ser que lhe deve as posições que ocupa no mundo.

A relação de um sujeito com o saber, além de incorporar os aspectos objetivos (conhecimento) presentes nos processos educativos e socioculturais, supõe, também, aspectos subjetivos marcados pela incidência do inconsciente.

Desde 1905, em "Três ensaios sobre a teoria da sexualidade", Freud (1905/1996a) associou o saber ao conflito edípico. A curiosidade sexual, que vinha sustentando a atividade intelectual na criança, sofre a ação do recalque e é sublimada, transformando-se em desejo de saber. O desejo de saber mantém um vínculo com a pulsão escópica que, desde o início, sustenta a curiosidade e as pesquisas sexuais da criança, confrontando-a com a diferença entre os sexos e com as cenas que adquirem uma significação sexual.

Freud constata que não existe na criança uma necessidade inata de causalidade que a levaria espontaneamente ao saber. $\mathrm{O}$ impulso ao saber é produto da urgência da vida. Para a psicanálise, a constituição do sujeito envolve o atravessamento de dois tempos distintos: o primeiro, do narcisismo, em que o bebê se faz objeto ilusório de completude para o Outro materno; e o segundo, do Complexo de Édipo, em que se opera uma separação sujeito/Outro, abrindo possibilidades para o surgimento do desejo.

Para que o bebê atravesse o primeiro momento, superando a ilusão de completude para o Outro materno, é preciso que essa confiança no Outro, bem como o saber absoluto que ele supõe nesse Outro, seja abalada, iniciando-se assim o processo de separação. Quando se descobre que esse Outro não é completo, descobrese também que algo falta ao próprio sujeito. É a partir da experiência de confronto com a falta no Outro que o sujeito se vê confrontado com a própria falta, levando-o a interpelar, a questionar, a buscar o saber, a constituir o próprio saber. É, portanto, a marca da falta do Outro, nomeada como castração, que impulsiona o sujeito em direção ao saber.

A castração do Outro seria a causa da divisão do sujeito, que o impele à busca de um saber sobre sua existên- 
cia e seu lugar no mundo. A criança é levada a empreender um trabalho de investigação, de pesquisa, quando se vê confrontada com a "questão-enigma" da origem dos bebês, a questão da sexualidade, da procriação, da diferença entre os sexos, ou da descoberta de que não é tudo para o Outro. Nesse momento, experimenta-se como um sujeito dividido.

A partir desse enigma sobre a origem dos bebês - para o qual as crianças elaboram perguntas do tipo "De onde vêm os bebês?", "Quem desejou esse bebê que vai ocupar o meu lugar?", "O que quer minha mãe?", "Eu não a completava?", “O que me falta, que eu não consigo satisfazê-la?" -, elas próprias respondem à maneira genial de um teórico, criando um grande número de mitos e lendas, inventando explicações que constituem uma de suas atividades sexuais.

As teorias sexuais infantis tendem a ser abandonadas: algumas serão esquecidas e outras, recalcadas e fixadas no inconsciente, constituindo assim o saber inconsciente, particular do sujeito e que determinará as modalidades permitidas ou proibidas de sua vida erótica. Dessa forma, constata-se que sexualidade e saber estão originalmente e intimamente ligados para o sujeito.

Em 1910, em seu estudo sobre Leonardo da Vinci, Freud (1910/1996b) indica uma outra razão para o recalque: um laço libidinal demasiadamente intenso com a mãe pode fixar no inconsciente uma teoria 
sexual infantil. É o que Freud lê, entre outras coisas, na lembrança de infância que Leonardo da Vinci conta em seus escritos. Ela dá testemunho da crença inconsciente na existência do pênis materno. $O$ recalcamento da sexualidade infantil assinala a entrada no período de latência. O que acontece, então, com o impulso ao saber? Nesse mesmo estudo, Freud lhe aponta três destinos: no primeiro, a investigação compartilha o destino da sexualidade. O desejo de saber permanecerá desde então inibido e a livre atividade da inteligência, limitada. Esse é o caso da inibição neurótica.

No segundo, a atividade intelectual escapa ao recalcamento, mas permanece ligada àquela busca inicial de sua investigação sobre a origem dos bebês. A partir de então, qualquer que seja o objeto de pesquisa intelectual, ela estará condenada a repetir o insucesso dessa primeira experiência. Ela se perderá em ruminações sem fim, acompanhadas pelo sentimento de que a solução buscada está cada vez mais longe.

O terceiro caso, o mais raro, escapa à inibição do pensamento, bem como à compulsão de pensar; é certo que o recalcamento sexual intervém, mas ele não consegue mandar para o inconsciente uma pulsão parcial do desejo sexual. É o caso, em Leonardo da Vinci, da pulsão escópica, que foi especialmente ativa na investigação sexual infantil. Nesse exemplo, a libido furta-se ao destino do recalque, sublimando-se, desde o início, em desejo de saber. A sublimação permite, então, que a pesquisa intelectual não repita o fracasso das investigações sexuais infantis, já que ela desvia a pesquisa de seu fim sexual.

Portanto, inibição, compulsão e sublimação constituem, para Freud, os três destinos da relação de um sujeito com o saber. É a verdade que se coloca no destino do sujeito em sua relação com o saber que a psicanálise vai buscar decifrar por meio de sonhos, chistes, atos falhos, sintomas, e que, mesmo decifrando-os, só o fará parcialmente, posto que essa verdade fala sobre sua relação impossível com o sexo. E é precisamente essa verdade que será rejeitada pelo discurso da ciência. Ao contrário, é do impossível da relação sexual que a psicanálise deve falar e extrair consequências.

Contudo, o desejo de saber se associa, também, à pulsão de dominação, que é descrita por Freud como uma pulsão não sexual, dirigida para o exterior e que constitui o único elemento presente na crueldade originária da criança. ${ }^{1}$ Freud chega a considerar que essa pulsão de dominação existiria em todo ser humano e se modi- 
ficaria, posteriormente, em sadismo e agressividade.

Para Lacan (1985), é no momento da entrada da criança na linguagem, em que a criança é confrontada com a questão crucial sobre sua origem, que surge também uma insaciável sede de saber. Essa sede de saber é ressaltada pelo adulto, quando este produz uma resposta de tipo científico à pergunta sobre a origem, na qual ele próprio não está implicado. Se, ao contrário, ele tenta se implicar, surge seu próprio embaraço diante da impossibilidade de ele dar conta de seu ser sexuado, produzindo uma resposta que se exprime, por exemplo, pelo mito da cegonha. Produz-se aí uma falta em lugar de uma resposta que ofereceria ao sujeito o acesso ao saber sobre sua origem, o que nos leva a pensar na impossibilidade de se produzir um saber total, que dê conta de tudo. As repostas para as nossas perguntas serão sempre parciais, pois haverá sempre um ponto no qual não encontraremos respostas. Para a criança, que ainda não dispõe de recurso quando se vê confrontada como sujeito ao enigma, ainda resta a ilusão de que, pela via do saber, seria possível preencher essa falta.

É a falta que impulsiona o sujeito a buscar, no social e no cultural, respostas para o que não tem como respondido. O que nós fazemos, então, desde a infância é tentar construir um saber que tampone esse furo que é estrutural. Mas a psicanálise afirma que não é possível preencher a falta com o saber, pois sempre haverá um resto impossível de ser acessado. Esse resto nos moverá numa busca constante.

Posto que o saber tem uma relação com o desejo, com o não todo, com a falta, podemos dizer também de sua disjunção com a verdade. Para Lacan (1988), a verdade é sempre uma ficção. Ela se instala a partir do que dizemos. Dessa forma, é sempre parcial, assim como o saber.

A relação de um sujeito com o saber, portanto, além de incorporar os aspectos objetivos, supõe também aspectos subjetivos marcados pela incidência do inconsciente.

Para aprender é preciso já saber um pouco, mas para saber é preciso ter previamente aprendido, de tal maneira que o saber é ao mesmo tempo o resultado e a condição da aprendizagem.

O saber é sempre um momento entre duas aprendizagens, aquele que a condiciona e aquele do qual ela resulta, e a aprendizagem é sempre um momento entre dois saberes, aquele que o torna possível, e aquele que ele torna possível. No filme I am Sam, todos os personagens desfilaram suas relações com o saber de maneira particular.

\section{Segregação e fixação: é possível evitar?}

Quando as práticas pedagógicas se aliam ao saber científico de 
médicos, psicólogos e pedagogos, acabam promovendo um discurso que nomeia como "fracasso escolar" todo e qualquer sintoma em relação ao saber e à aprendizagem. Embora cheio de boas intenções para com as crianças, o que esse discurso acarreta é, por um lado, a fixação em discursos prontos e, por outro, a segregação. Uma das teses de Lacan (1992) indica que há um componente estrutural inerente à segregação, visto que a própria linguagem segrega o real. Em tempos pós-modernos, em que pensar e agir rapidamente se tornaram a ordem do dia, dificilmente há espaço e lugar para as pessoas que apresentam características de lentidão e certa letargia, como é o caso de Sam no filme.

A primeira teorização sobre as dificuldades de aprendizagem, surgida no final do século XIX e sempre citada como a grande responsável pela medicalização generalizada do fracasso escolar, buscou nas disfunções neurológicas ligadas ao desenvolvimento do sistema nervoso central a causa dos problemas de aprendizagem, classificando todos os casos sob a rubrica de "dislexia" e de “disfunção cerebral mínima”. Essas duas patologias, bastante imprecisas do ponto de vista de suas etiologias, tornaram-se duas categorias que, ao serem aplicadas no campo da educação, promovem a segregação. Empregadas para justificar as dificuldades e, também, a interrupção da escolaridade normal, ambas agem no sentido de atestar o déficit do lado do sujeito (Santiago, 2005). No filme, a dificuldade de aprendizagem manifestada por Lucy foi atrelada à deficiência de seu pai. Essa via diagnóstica interrogou a possibilidade de Lucy aprender na escola por ter um pai com deficiência, mas podemos apontar que a leitura psicanalítica tomaria a questão como um sintoma, pois Lucy se coloca na posição de não poder ultrapassar seu pai, portanto em uma posição de inibição diante do saber. A pregnância da ideia de um desenvolvimento infantil ancorado no biológico faz com que as concepções sobre o desenvolvimento psíquico sejam encaradas na mesma ótica: a de um psiquismo que vai evoluindo segundo a evolução do corpo.

Tanto a assistente social quanto o setor jurídico - ao indicar a separação entre pai e filha, entendendo que havia certo contágio da deficiência do pai em relação à aprendizagem da filha -, além de suprimirem a emergência do particular, autorizam o saber científico a tratar o sujeito como objeto de estudo, retirando do sujeito a possibilidade de inventar seu próprio sintoma. A clínica psicanalítica em seu saber sobre o caso a caso interrogaria os discursos que fixaram Lucy à condição de não aprendizagem, bem como o seu sintoma de inibição intelectual diante de um pai com deficiência. No caso, seria pertinente interrogar em que medida Lucy estava identificada com seu pai, considerando que as primeiras identificações efetuadas na primeira infância são, para Freud, duradouras 
e esclarecedoras da posição de um sujeito em relação ao saber. Nessa lógica discursiva, as especificidades concernentes a cada sujeito dizem respeito não a um desenvolvimento, mas aos movimentos da estrutura que já está fundada. Essa outra lógica altera radicalmente a representação de criança e aqui também a representação de deficiência que antecede ao sujeito.

Para a clínica psicanalítica, o inconsciente é atemporal, só havendo psicanálise do sujeito. Sendo assim, a psicanálise descarta a linearidade entre a maturação orgânica e a constituição subjetiva. Tanto Sam quanto Lucy escapam a essa linearidade. A condição de criança ou de deficiente mental não impede que vários modos de resposta ao ideal social sejam produzidos. No filme, as falhas que se apresentam em Lucy através da não aprendizagem serviriam para interrogar sua posição identificatória com seu pai e seu sintoma. Cabe ao analista ir além desse estatuto de criança e de deficiente que é dado pelo social para encontrar a questão de como cada um tem se organizado e se constituído como sujeito. Seria preciso que o analista fizesse uma escuta das modalidades de resposta que o sujeito produz e que se manifestam pela via do sintoma. Há que se produzir um descolamento do lugar que a criança ocupa na trama fantasmática do Outro, bem como propiciar a construção que o sujeito possa fazer de seu próprio fantasma. À psicanálise cabe interrogar o sujeito sobre a posição que ele toma diante do que o determina, a despeito de sua pouca idade ou da deficiência: o ponto comum a ser interrogado é a recusa de ambos ao que é da ordem do saber.

Se tomarmos o discurso de Freud (1937/1996) em relação à educação e ao impossível do ato de educar, concluímos que a psicanálise qualifica as modalidades de ato cujo efeito não se pode antecipar como o governar e o analisar. Assim também ocorre na educação: o educador transmite um determinado conhecimento para um grupo de alunos, mas o resultado dessa transmissão não é previsível nem passível de um cálculo coletivo. Da parte dos alunos, observa-se que uns aprendem, outros não. Às vezes, o aprendizado é marcado por sérias distorções, por erros grosseiros resultantes de equivocação ou, simplesmente, por não aprendizado. O professor, por sua vez, sobretudo a partir a análise das avaliações, nota que os alunos, muitas vezes, conferem ao conteúdo uma ênfase distinta ou oposta àquela que ele pretendeu ressaltar. Outras vezes, a atitude dos alunos de aceitação, desafio, provocação ou recusa da pessoa do professor é que determina as relações de aprendizagem. Sejam 
quais forem os métodos pedagógicos utilizados, quando admitimos a existência do inconsciente, não é possível fixar uma relação de causalidade entre os meios e os efeitos obtidos.

Esses fenômenos, entre tantos outros observados na esfera da missão de educar, ilustram o ato impossível, que, para a psicanálise, é delimitado por uma intenção para além da consciência e cuja consequência é uma resposta que implica o inconsciente daquele a quem foi endereçado.

Quando o pedagogo imagina estar se dirigindo ao Eu da criança, "o que está atingindo, sem sabê-lo, é o seu inconsciente; e isso não ocorre pelo que crê comunicar-lhe, mas pelo que passa do seu próprio inconsciente através de suas palavras" (Millot, 1987, p. 150). ${ }^{2}$ Podemos nos perguntar o que essa outra leitura poderia gerar na produção de um filme que pretendeu tratar a deficiência mental fixando o sujeito em uma posição deficitária e atrelando a construção de saber da criança à essa posição deficitária, corroborando uma representação de criança e de deficiente como um "ser inacabado", "imaturo", cujo aparelho psíquico vai se desenvolver no balanço do desenvolvimento biológico, o que no filme estava posto tanto para Sam quanto para Lucy.

$\mathrm{Na}$ leitura psicanalítica ao que se passa entre pais e filhos, entre professores e alunos, independentemente da dimensão objetiva dos sujeitos, interpõe-se, sempre, um verdadeiro intercâmbio de elementos inconscientes, fantasmáticos, que podem ser apreendidos apenas a partir da manifestação de uma desordem qualquer. Nesse sentido, o diagnóstico freudiano permite postular o fracasso como signo do que não cessa de não se escrever na vida desses sujeitos. A tarefa do discurso analítico, diante disso, consiste em tentar fazer desse impossível um sintoma, para além das determinações orgânicas ou cognitivas imputadas pelo discurso da ciência como fonte de um déficit do sujeito.

Aqui o cinema foi o instrumento que usamos para transmitir algo da diferença subjetiva que nos constitui a todos. Na perspectiva da inclusão, tão em voga nos dias atuais, algo da diferença deveria ser tomado como irredutível: se consideramos o sujeito do inconsciente tanto a pessoa com deficiência quanto a que não a possui, ambos estariam posicionados diante da debilidade como um mal-estar fundamental do sujeito em sua relação com o saber. 
'T AM SAM": MENTAL RETARDATION AND THE RELATION WITH KNOWLEDGE

\begin{abstract}
The movie "I am Sam" is about mental disability and the social representations that surround it. Initially, the article presents the definition of mental retardation from a universal perspective and discusses the differences between learning disability, school failure and weakness from the perspective of psychoanalysis considering the child's relationship with knowledge. The goal of this paper is to use films and the filmography available in order to interrogate fixed and segregational diagnoses that exclude the subject and its relationship to knowledge.
\end{abstract}

Index terms: disability; subject; relationship with knowledge.

\section{"I AM SAM": DISCAPACIDAD MENTAL Y RELACIÓN COM EL SABER}

\section{RESUMeN}

La pelicula "Yo soy Sam" viene de las representaciones mentales y sociales de discapacidad que lo rodean. Inicialmente, el articulo presenta la definición de retraso mental en una perspectiva universal y cotejar la diferencia entre la deficiencia, la debilidad y el fracaso escolar mentales desde la perspectiva del psicoanálisis considerando la relación del niño con el saber. Utilizando el cine y la filmografía disponibles para interrogar diagnósticos fjos y segregación que excluye le sujeto y su relación con el saber el objetivo de este trabajo.

Palabras clave: discapacidad, sujeto, relación con el saber.

\section{REFERÊNCIAS}

Bruno, P. (1986). A côté de la plaque. Sur la débilité mentale. Ornicar? Revue du Champ Freudien, 37, 38-65.

Freud, S. (1996a). Três ensaios sobre a teoria da sexualidade. In S. Freud, Edição standard brasileira das obras psicológicas completas de Sigmund Freud (J. Salomão, trad., Vol. 7, pp. 129-266). Rio de Janeiro: Imago. (Trabalho original publicado em 1905)
Freud, S. (1996b). Leonardo da Vinci e uma lembrança da sua infância. In S. Freud, Edição standard brasileira das obras psicológicas completas de Sigmund Freud (J. Salomão, trad., Vol. 11, pp. 59-126). Rio de Janeiro: Imago (Trabalho original publicado em 1910)

Freud, S. (1996c). Análise terminável e interminável. In S. Freud, Edição standard brasileira das obras psicológicas completas de Sigmund Frend (J. Salomão, trad., Vol. 23, pp. 247-292). Rio de Janeiro: Imago (Trabalho original publicado em 1937)

Freud, S. (1996d). Além do princípio do prazer. In S. Freud, Edição standard brasileira das obras psicológicas completas de Sigmund Freud (J. Salomão, trad., Vol. 18, pp. 17-90). Rio de Janeiro: Imago (Trabalho original publicado em 1920)

Lacan, J. (1985). O seminário, livro 2: o eu na teoria de Freud e na técnica da psicanálise, 1954-1955 (A. Menezes, trad.). Rio de Janeiro: Jorge Zahar.

Lacan, J. (1988). Posición del inconsciente. In J. Lacan, Escritos 2 (pp. 808-833). México: Siglo XXI.

Lacan, J. (1992). O seminário, livro 17: o avesso da psicanálise (A. Roitman, trad.). Rio de Janeiro: Jorge Zahar.

Millot, C. (1987). Freud antipedagogo. Rio de Janeiro: Zahar.

Organização Mundial de Saúde. (2011). Estatísticas Mundiais de Saúde 2011. Recuperado em 20 de janeiro de 2013, de www.onu.org.br Organização das Nações Unidas. (2011). Relatório sobre a Situação Social Mundial 2011. Recuperado em 20 de janeiro de 2013, de www.onu.org.br

Santiago, A. L. (2005) A inibição intelectual na psicanálise. Rio de Janeiro: Jorge Zahar.

\section{NOTAS}

1. Na descrição do autor, a pulsão de dominação poderia se fundir, secundariamente, com a sexualidade. Em "Além do princípio do prazer" e com a introdução da pulsão de morte, Freud (1920/1996d) descreve a gênese 
do sadismo como uma derivação para o objeto da pulsão de morte, que originalmente, visa a destruir o próprio objeto.

2 A respeito do ato de educar como um agir sobre o inconsciente do outro por meio da palavra, Millot cita uma fala de Sigmund Freud, em $A$ disposição à neurose obsessiva: "Afirmei que todo homem possui, em seu próprio inconsciente, o instrumento com o qual é capaz de interpretar as manifestações do inconsciente no outro" (Millot, 1987, p. 155).

dinizmargareth@yahoo.com.br Rua Francisco Lobo, 476 30280-080 - Belo Horizonte - MG- Brasil.

Recebido em fevereiro/ 2013. Aceito em maio/2013.

296 Estilos clin., São Paulo, v. 18, n. 2, mai./ago. 2013, 279-296. 